while considered to be reduced. It formed a faecal fistula, which eventually closed spontaneously. Thus our use of the term Richter's hernia to describe ischaemic damage to only part of the circumference of the bowel wall after unrecognised incomplete reduction of a hernia seems to be historically correct.

TONY SPARNON EDWARD KIELY LEWIS SPITZ

Department of Surgery,

The Hospital for Sick Children,

Great Ormond Street, London WC1N 3JH

1 Watson LF. Hernia. 3rd ed. London: Henry Kimpton, 1984:102.

2 Keynes WM. Richter's and Littre's hernias. In: Nyhus LM Condon RE, eds. Hernia. 2nd ed. Philadelphia: J B Lippincott, 1978:320.

\section{Sources and patterns of referral of oral cancer}

SIR,--Professor L Scully and colleagues highlight some of the problems associated with the recognition and referral pattern of cancer of the oral cavity (6 September, p 599). They rightly emphasise the need for early diagnosis and treatment, which should lead to better "cure rates." Cancer or suspicious lesions in the oral cavity are generally symptomatic or visible to the patient at an early stage and can readily be biopsied without the need for admission to hospital. Unfortunately, these statements cannot be made about most of the other cancers of the head and neck area. Tumours, benign and malignant, arising in the pharynx and larynx manifest themselves by vague symptoms of hoarseness or the sensation of a "lump in the throat." Too often such patients make their own diagnosis of laryngitis or pharyngitis (frequently supported by practitioners), which results in delayed referral until the lesion has increased significantly or spread to affect the cervical nodes. Most general practitioners have neither the equipment nor the skill to examine the pharynx or larynx with confidence to rule out a suspected diagnosis of cancer. All patients with symptoms referrable to their "throat" that have persisted for longer than four weeks should be diagnosed correctly, or at least have the diagnosis of cancer eliminated, before further treatment is continued.

Currently in the United Kingdom the incidence of head and neck cancer (squamous cell carcinoma) is $60 /$ million population/year. The distribution according to anatomical sites is $40 \%$ larynx, $40 \%$ oral cavity, and $20 \%$ other sites. Laryngologists suggest that if a patient had a choice of developing a malignant growth (other than skin cancer) the growth to develop would be a neoplasm of the larynx. ${ }^{1}$ This is because the neoplasm presents early with the symptom of hoarseness, it can easily be confirmed by indirect laryngoscopy, and treatment with radiotherapy can give a five year "cure rate" of $92 \%$

In clinical practice doctors (general practitioners) refer to doctors (in hospital) and dentists (dental practitioners) refer to dentists (oral surgeons). One successful way to overcome this problem is to encourage hospital staff who are interested in the management of patients with head and neck cancer to come together in one clinic-a combined head and neck oncology clinic-which will usually include staff in otolaryngology, oral surgery, radiotherapy, speech therapy, and pathology. If run weekly such a clinic can cope with all the old patients for regular follow up and can see new referrals on an "open clinic" basis to practitioners. This clinic minimises the delay in referral, improves the quality and speed of diagnosis, and frequently reassures many patients suspected of having a tumour that this is not so. It is only by setting up such combined clinics that any attempt can be made to reduce the morbidity and appreciable mortality associated with head and neck cancer.

Combined Head and Neck Oncology Clinic,

P J BRADLEY

University Hospital, Notuingham NG7 2UH

1 Stell PM, Dalby JE. The treatment of early (T) glottic and supraglottic carcinoma. Eur F Surg Oncol 1985;11:263-6.

\section{Why not add methionine to paracetamol tablets?}

SIR,-The excellent leading article by $\mathrm{Dr} T \mathrm{~J}$ Meredith and colleagues (9 August, p 345) highlights the fact that deaths from paracetomol poisoning are not uncommon, although official statistics probably overestimate the number. Antidote treatment is efficacious only if given within 10-12 hours after ingestion of the drug. Thus the logical method of preventing paracetamol intoxication is to add methionine to paracetamol tablets and capsules-a possibility Dr Meredith and his coauthors did not consider.

Because the administration of an antidote is often delayed by more than the critical time we tested the possibility of adding methionine to paracetamol tablets directly. Methionine did not decrease the analgesic efficacy of paracetamol but decreased its toxicity by $50 \%$ on average in nonfasted animals, fasted animals, and animals treated with phenobarbital. ${ }^{1}$ Addition of methionine $(20 \%$ by weight) to the paracetamol tablets did not change the bioavailability of paracetamol in man. ${ }^{1}$ In a paracetamol-methionine combination the dose of methionine increases automatically with the dose of paracetamol. Furthermore, the protective effect of methionine is immediate; the time lag in giving the antidote is missing, and methionine is absorbed at least as rapidly as paracetamol.'

It is reasonable to assume that the addition of methionine, an essential amino acid, to paracetamol tablets in doses not exceeding its recommended daily intake would save the lives of many patients when the specific antidote is not available early enough. Use of methionine in products containing paracetamol should be considered and the pharmaceutical companies encouraged to develop less toxic formulations of paracetamol.

PertTi J Neuvonen

Department of Clinical Pharmacology,

University of Helsinki

OLLI Simell

Department of Nutrition

University of Kuopio

Huhtamäki Oy Pharmaceuticals,

Olavi Tokola

Helsinki, Finland

1 Neuvonen PJ, Tokola O, Toivonen M-L, Simell O. Methionine in paracetamol tablets, a tool to reduce paracetamol toxicity. Int f Clin Pharmacol Ther Toxicol 1985;23:497-500.

\section{Manpower}

SIR,-The new medicopolitical year has brought a flurry of meetings on the manpower document Hospital Medical Staffing: Achieving a Balance, which was published just too late for discussion by the annual conferences. It was subsequently approved in principle by the Central Committee for Hospital Medical Staff and the Hospital Junior Staff Committee, using an unusual procedure whereby the new document was handed out at the beginning of the committee meeting and collected in at the end. Traditionally members of craft committees would wish to discuss matters of such moment with their constituents before coming to a decision-even in principle.
The central feature of the document is the creation of a new subconsultant grade-arguably a necessary innovation in the light of the prolonged and total failure of the profession and DHSS to achieve a sensible hospital staffing structure but none the less strange in view of the fact that one week previously the representative body, meeting in Scarborough, had firmly rejected a motion to introduce just such a grade.

Even accepting the principle of this about turn in medical staffing, the numbers simply do not add up. The relatively small number of doctors in the new grade (increasing to $10 \%$ of total consultant numbers) would not in any way make up for the massive contraction in registrar numbers, which will occur when only "regional registrars" (directly related to senior registrar numbers) and "district registrars" (overseas doctors training scheme) are the only sorts of registrars in existence. Either the numbers of doctors in the new grade will turn out to be much larger than $10 \%$ of consultant numbers or the document will in fact produce "Short by stealth"-a solution considered unacceptable to the profession in the past.

Two myths have been widely propagated. The first is that the new plan is a package which must be either accepted or rejected. In reality it is a reasonable first attempt which needs much discussion and refinement, assuming that the basic principle of the introduction of a subconsultant grade is acceptable to the profession. The chairman of the CCHMS is due to change and the Minister for Health has been replaced. I have no doubt that their successors will have their own ideas for modifying the scheme. Even now the concepts of regional and district registrars have attracted wide criticism and need to be rethought. The second myth is that the profession is incapable of analysing and criticising the proposals in a responsible manner. Such criticism is vital if the scheme is to win the hearts and minds of the doctors who will have to operate it. If the document cannot stand up to such inspection it deserves to fail. The least the BMA can do is to hold a special representative meeting to discuss the matter. Such a meeting must be held if $30 \mathrm{BMA}$ divisions so request. I invite divisional secretaries to bear this in mind when constructing agendas for their autumn meetings.

J N Johnson Deputy Chairman, Conference of Honorary Secretaries of BMA Divisions

Halton General Hospital,

Runcorn, Cheshire WA7 2DA

SIR,-I have recently attended several meetings regarding the important document on manpower. On each occasion I have been told that the DHSS attitude is that the principles of the proposals are not negotiable and that consultation is to be confined to details of implementation. We are enjoined to regard the proposals as a package; the acceptance of some points on which we may have grave reservations is the necessary price to be paid to obtain a solution to our manpower problems.

I object to both these attitudes. The Department of Health and Social Security seems to feel that it has the agreement of the profession whereas it actually has the agreement of some of the representatives of some parts of the profession. Consultation was not widespread or prolonged and many of us are deeply concerned at the implication of these proposals. I agree that some of the proposals are welcome but feel that the unacceptable elements outweigh the good ones and that the total package is therefore unacceptable to me. I believe that many others share this view but that we are all in danger of implicitly accepting the package if we enter into consultation on the details. 